\section{Two sides of the same System? A study of the senses of 'Sistema Único de Saúde' in Diário do Nordeste newspaper}

\title{
Duas faces do mesmo Sistema? Um estudo dos sentidos do Sistema Único de Saúde no jornal Diário do Nordeste
}

ABSTRACT | Introduction: The Unified

Health System is the only way to access health actions and services for about 150 million Brazilians. As a subject of public interest, it is constantly present in the media, appearing in various ways and from multiple discursive strategies in journalism. Objectives: To understand the ways in which the newspaper

Diário do Nordeste constructed senses about the Unified Health System. Methods: Qualitative analysis of journalistic texts based on the theoretical and methodological reference of the Semiology of Social Discourses, favoring authors such as Pinto, Bourdieu and Bakhtin. After collecting the texts that contained the expression Unified Health System, eight articles containing linguistic marks representing the mapped senses were selected for discursive analysis. Results: Among the main results, it was observed that

Diário do Nordeste composed ways of writing about the Unified Health System based on discursive strategies of criticism, but also on recognition of the System. The senses of criticism were based on the visibility conferred to the absence of technologies in the health services and the precariousness in its financing; and those of recognition were constructed by the recovery of the efficacy and the tradition of certain health services, always taking into account the political contexts in which they stand. Conclusion: The presence of criticism, but also of the recognition of SUS, pointed out that the senses produced by the media are not only characterized by the negative view on the Unified Health System, but are also marked by ambiguity. It is possible to understand this discursive production, by relating it to its contexts and understanding the media as an important current political actor.

Keywords | Journalism; Health; Unified Health System; Addresses; Communication.
RESUMO| Introdução: O Sistema Único de Saúde se configura como a única possibilidade de acesso às ações e aos serviços de saúde para cerca de 150 milhões de brasileiros. Enquanto tema de interesse público, tem presença constante na mídia, figurando no jornalismo de diversas maneiras e a partir de múltiplas estratégias discursivas. Objetivos: Compreender os modos pelos quais o jornal cearense Diário do Nordeste construiu sentidos sobre o Sistema Único de Saúde. Métodos: Análise qualitativa de textos jornalísticos baseada no referencial teórico-metodológico da Semiologia dos Discursos Sociais, privilegiando autores como Pinto, Bourdieu e Bakhtin. Após coleta dos textos que continham a expressão Sistema Único de Saúde, foram selecionadas para análise discursiva oito matérias que contêm marcas linguísticas representativas dos sentidos mapeados. Resultados: Entre os principais resultados, observou-se que o Diário do Nordeste constituiu modos de falar sobre o Sistema Único de Saúde com estratégias discursivas de crítica, mas também de reconhecimento ao Sistema. Os sentidos de crítica se teceram com base na visibilidade conferida à ausência de tecnologias nos serviços de saúde e à precariedade no financiamento; e os de reconhecimento foram construídos pelo resgate da eficácia e da tradição de determinados serviços de saúde, levando-se sempre em consideração os contextos políticos nos quais se situam. Conclusão: A presença da crítica, mas também do reconhecimento do SUS, apontou que os sentidos produzidos pela mídia não se caracterizam apenas pela visão negativa acerca do Sistema Único de Saúde, sendo marcados pela ambiguidade. Cabe entender essa produção discursiva relacionando-a com seus contextos e compreendendo a mídia como um importante ator político na atualidade.

Palavras-chave | Jornalismo; Saúde; Sistema Único de Saúde; Discursos; Comunicação.

${ }^{1}$ Fundação Oswaldo Cruz. Rio de Janeiro/RJ, Brasil. 


\section{INTRODUÇÃO|}

Em 2014, de acordo com a Agência Nacional de Saúde Suplementar ${ }^{1}$, o número de usuários de planos privados de assistência à saúde chegou a um total de 51 milhões de pessoas, o que representava uma cobertura de $26,3 \%$ da população. Mesmo considerando a possibilidade de crescimento desse percentual até hoje, esse número significa que o Sistema Único de Saúde ainda se configura como a única possibilidade de acesso às ações e aos serviços de saúde para mais de 150 milhões de brasileiros. Esse cenário se torna ainda mais agudo se levarmos em conta as centenas de pessoas que, mesmo portadoras de planos privados, são acolhidas pelas políticas e pelos serviços do Sistema Único de Saúde quando a cobertura de suas operadoras se mostra deficiente ou limitada. Mas sua importância não se restringe à oferta de procedimentos. Enquanto política de Estado, assegurada pela Constituição Federal, o Sistema Único de Saúde tem o desafio de estruturar, além da assistência, a promoção, proteção e prevenção da saúde, e possui a prerrogativa de ordenar a força de trabalho e a formação de profissionais por todo o território nacional.

Em termos históricos é importante lembrar que, antes do Sistema Único de Saúde, a integralidade a partir de níveis de atenção à saúde - que se configurou como um de seus princípios - não existia no cenário brasileiro, como também não existia uma aposta na universalidade, na opção de construir uma política de saúde para a assistência a todos os cidadãos. A população pobre, quando era assistida, o era por entidades filantrópicas, geralmente vinculadas à Igreja, "por conta da caridade cristã, que abrigava indigentes, viajantes e doentes"2 (p. 26). No entanto, a implantação do Sistema Único de Saúde, como política de Estado, sempre se constituiu como um cenário tenso de lutas e de disputas de poder. Não havia, à época da Reforma Sanitária, e não há, ainda hoje, esgotamento dos temas geradores ou consenso em torno da composição ideal do Sistema. Sua implantação se deu num território de contradições e disputas, mesmo entre seus defensores originários, e sua sustentação carrega essa herança.

Tamanhas complexidade e relevância histórica, social e econômica se refletem na presença do Sistema Único de Saúde nos meios de comunicação, sendo este um tema recorrente na cobertura noticiosa dos jornais brasileiros. E também no interesse pelo tema nas pesquisas sobre mídia. Nota-se, contudo, que essa presença e interesse são marcados frequentemente pela apresentação de um Sistema sucateado, com pouca mão de obra disponível, envolvido em esquemas de corrupção, sem a existência de tecnologia de ponta, e que exceto por um ou outro procedimento mais complexo realizado, só gera uma sensação de abandono e desrespeito perante os contribuintes brasileiros. Um Sistema cuja imagem é fortemente associada à espera, à ineficiência e à morte de seus usuários, por exemplo, os que são retratados nos corredores das emergências aguardando atendimento. Isso pode ser visto tanto a partir de uma leitura corriqueira dos jornais ou da exposição aos programas de televisão, com seus perfis voltados à valorização do factual e ao exercício da denúncia quanto em trabalhos acadêmicos que destacam as estratégias de negativar e/ou invisibilizar o Sistema Único de Saúde, praticadas pela mídia como modos de representação da realidade sobre a saúde pública brasileira ${ }^{3,4,5,6,7}$.

Santiago $^{3}$, ao pesquisar os temas mais explorados pelos periódicos cearenses na produção de notícias sobre saúde, conclui que as filas do Sistema Único de Saúde figuram entre os mais expressivos quantitativamente. Também Silva ${ }^{4}$, ao analisar a Folha de São Paulo, se depara com uma extensa produção de sentidos de ineficácia do Sistema Único de Saúde e incompetência do governo nas notícias sobre saúde pública. Menegon ${ }^{5}$, considerando os sentidos produzidos sobre o Sistema Único de Saúde em jornais impressos de Campo Grande (MS), percebeu que a crise nos serviços de saúde foi um dos dois temas de maior destaque da cobertura, no período analisado.

Xavier e Narvai ${ }^{6}$ apontam que além de enfatizar os serviços de saúde nos quais a vulnerabilidade de seus usuários está mais exposta, como os transportes e atendimentos de emergência, a cobertura midiática majoritariamente promove a invisibilidade do Sistema Único de Saúde, quase nunca identificando a presença da sua logomarca nos estabelecimentos que visita. Lefèvre e $\mathrm{Caron}^{7}$, ao analisar notícias sobre saúde divulgadas pelo Jornal Nacional, também verificam uma ênfase na precariedade dos estabelecimentos do Sistema Único de Saúde, especialmente alguns de seus hospitais, ao mesmo tempo em que promovem a invisibilidade do Sistema nas matérias que mostram suas realizações positivas. E Oliveira ${ }^{8}$, propondo uma reflexão sobre a relação entre Sistema Único de Saúde e mídia, afirma que sendo ela representante dos grupos de poder na sociedade ou favorável a eles,

\footnotetext{
[...] se mostra mais preocupada em produzir noticias que revelem os desvios do Sistema Único de Saúde do que as mudanças substantivas que ele pode provocar no cenário social (p. 76).
} 
Narrativas concorrentes sobre o Sistema Único de Saúde, contudo, estão presentes no espaço público; por exemplo, o levantamento realizado em 2011 pelo Instituto de Pesquisa Econômica Aplicada (Ipea) sobre a satisfação dos usuários do SUS diante dos serviços públicos assistenciais? Esse estudo apontou que 80,7\% dos entrevistados cujos domicílios foram visitados por algum membro da Equipe de Saúde da Família opinaram que o atendimento prestado é muito bom ou bom, enquanto somente 5,7\% dos entrevistados disseram que é ruim ou muito ruim. Outras iniciativas como a distribuição gratuita de medicamentos e o atendimento por médicos especialistas também foram qualificadas como muito boa ou boa por 69,6\% e 60,6\% dos entrevistados, respectivamente. Narrativas desse tipo, que favorecem a formulação de noções positivas sobre o Sistema Único de Saúde, eventualmente são consideradas pela mídia para publicação em seus dispositivos jornalísticos. A matéria Classe média se surpreende com o "SUS que funciona"10 e a série SOS SUS ${ }^{11}$ ilustram essa afirmação. Nesse sentido, Machado $^{12}$ pondera ser importante reconhecer que nem toda cobertura sobre o Sistema Único de Saúde é negativa, e que, "notoriamente mais timidamente", há espaço midiático para a circularidade de textos que destacam percepções positivas sobre o Sistema, ainda que sempre em partes consideradas promissoras do Sistema, e "nunca em sua totalidade".

O interesse em compreender a construção da realidade pela mídia mediante múltiplas estratégias discursivas resultou na dissertação de mestrado intitulada "Os sentidos do Sistema Único de Saúde na mídia impressa do Ceará - Um estudo do jornal O Diário do Nordeste" ${ }^{\text {"13 }}$, da qual retiramos os dados aqui analisados.

Este artigo parte, portanto, desse conjunto de preocupações, e tem como objetivo analisar os sentidos do Sistema Único de Saúde em um jornal impresso dotado de modernas estruturas de produção, com ampla circulação regional e que se configura como um importante ator político no contexto social no qual se situa.

\section{MÉTODOS|}

Para realizar essa análise, foi executada uma pesquisa documental tendo como objeto empírico o jornal Diário do Nordeste. Criado em 1981, pertence ao maior grupo de mídia do Ceará, o Sistema Verdes Mares - o qual, além do jornal impresso, possui uma rádio AM, uma rádio FM, um portal de notícias, um canal de televisão regional e é o retransmissor regional da rede Globo. Ademais, é o único jornal com distribuição em 100\% do Estado ${ }^{14}$. Essa ampla capacidade de circulação, maior do que a de todos os outros periódicos locais, associada à possibilidade de coleta online das edições virtuais, determinou a escolha desse periódico para fins de análise.

Para constituir o corpo original da pesquisa, tomamos como objeto de investigação os textos produzidos pelo Diário do Nordeste durante o período de 01 janeiro a 30 de junho de 2013, que se referiram ao Sistema Único de Saúde mediante sua nomeação (pela sua sigla ou expressão completa). Considerando que o ato de nomear é um ato de reconhecer a existência, pensamos ser importante considerar as ideologias que atravessam essa experiência de nomeação: ao chamar de Sistema Único de Saúde, o jornal faz emergir um sujeito histórico dotado de forte memória discursiva, e que convoca referências sobre si de modo a continuamente dotá-las de sentidos.

A escolha dos textos foi realizada a partir da leitura das edições virtuais do jornal Diário do Nordeste, com foco nos espaços editoriais que previamente avaliamos como quantitativamente prevalentes de aparição do tema: as capas; o Primeiro Caderno - com as editorias de Opinião, Cidade, Política, Nacional; o caderno Regional, pela relevante caracterização das demandas do interior do Estado; e o caderno Vida, que se define como o suplemento de saúde do jornal. Essa etapa resultou na coleta de 132 unidades de análise, entre notas, notícias, reportagens, editoriais, colunas e artigos de opinião.

Para compreender os modos pelos quais o Diário do Nordeste falou sobre o Sistema Único de Saúde e produziu, assim, efeitos de sentidos sobre ele, fizemos um levantamento das expressões linguísticas presentes nos enunciados textuais, que conformaram operações discursivas a partir das quais se estruturou a produção de sentidos. O uso de adjetivos, qualificando os objetos e sujeitos, a aplicação de conjunções que caracterizam adversidades e potências e o destaque de elementos tomados como positivos ou negativos pelo senso comum foram algumas das estratégias que marcaram essas operações, resultando na composição por saturação de três (3) regularidades discursivas: a) de crítica e de reconhecimento ao Sistema Único de Saúde; b) de produção de vigilância sobre a gestão do Sistema e sobre a vida dos indivíduos; c) de mediações políticas e com os 
políticos em todas as dimensões geográficas registradas nos textos (municípios, Estado, União).

Para este artigo, os modos de falar que serão abordados referem-se ao primeiro grupo de regularidades discursivas: sobre a produção de sentidos contraditórios de crítica e de reconhecimento do Sistema Único de Saúde. Ao lançar um olhar sobre os discursos presentes no Diário do Nordeste, constatamos que o periódico realizou a crítica ao Sistema Único de Saúde nomeado principalmente com base na construção dos sentidos de ausência e precariedade, e exerceu um reconhecimento e uma legitimação do Sistema Único de Saúde a partir dos sentidos de eficácia e de tradição atribuídas aos contextos situacional imediato, do ponto de vista da práxis do Sistema Único de Saúde; e muitas vezes também ao seu contexto ideológico, problematizando suas diretrizes constitutivas e seus mecanismos de gestão, de financiamento, de funcionamento. Para a análise aqui exposta foram selecionados oito (8) textos que apresentam marcas discursivas (são as palavras que aparecem em itálico nos enunciados) representativas dos efeitos especificados: ausência (2 textos), precariedade (3 textos), eficácia (2 textos) e tradição (1 texto).

Tomando como referencial a Semiologia dos Discursos Sociais, nossa análise estabelece como ponto de partida o texto publicado, sua gramática e semântica, e as demais pistas materiais que podem ser encontradas na superfície componente da página do jornal, como suas imagens e padrões gráficos, que muito revelam sobre as práticas culturais que lhes deram origem ${ }^{12}$. Assim, além da leitura do conteúdo jornalístico, coube-nos verificar o modo como esse texto produz uma relação dialógica com os demais textos que ocupam a mesma superfície espacial do periódico e com a memória de outros textos que os antecederam, ressignificando os sentidos da nomeação do Sistema Único de Saúde a cada nova enunciação ${ }^{15}$.

\section{RESULTADOS/DISCUSSÃO|}

Para entendermos de que maneira tais estratégias se desenvolvem, estamos propondo um caminho, que é justamente o entendimento da prática jornalística como um fenômeno social: como prática social discursiva. E os textos jornalísticos como discursos, que constroem sentidos sobre tudo o que incorporam e transformam em acontecimento. Tal concepção implica dizer que, ao produzir conteúdos jornalísticos, toda a gama de sujeitos que está envolvida nas práticas jornalísticas - os proprietários de mídias, os jornalistas, os colaboradores convidados, os especialistas convocados etc. - estão também produzindo efeitos de sentido sobre a vida cotidiana, interferindo na compreensão e na própria fluidez dos acontecimentos. Mas essa prática discursiva não é homogênea, não é estática, tampouco é linear. Suas modulações dependem dos contextos - sociais, econômicos, existenciais - nos quais estão inseridas, com os quais de misturam e mutuamente se modificam.

Em termos gerais, esse entendimento nos leva a compartilhar da ideia de que a presença da mídia na atualidade se configura na conformação de um tipo de poder. Neste caso, o poder de constituir a própria ideia de cotidiano, a partir do cotidiano em si, e de nos oferecer elementos para construir e sustentar essa continuidade. $\mathrm{Ou}$, quem sabe, provocar nela rupturas. $\mathrm{O}$ exercício do poder midiático, diferentemente dos poderes concretos existentes, estabelecidos muito mais pela imposição física da força, se dá pela disputa e pela negociação simbólica dos modos de fazer ver determinadas coisas e fazer crer no que se diz sobre elas. A esse respeito, Bourdieu ${ }^{16}$ consagrou a expressão 'poder simbólico', indicando que

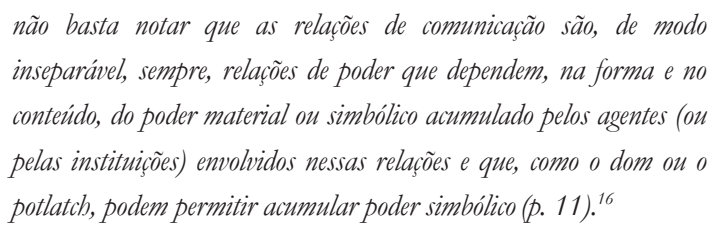

Assim, os sujeitos das relações de comunicação estruturam suas disputas de ingressos naquilo que Araujo ${ }^{17}$ denominou de mercado simbólico: o território onde várias vozes concorrem entre si pela prevalência do seu próprio modo de perceber, analisar e intervir sobre a realidade. Nesse mercado se negociam e se põem a circular não apenas significados exatos sobre os temas, mas também efeitos de sentidos ancorados em ideologias que habitam o imaginário coletivo, fortalecendo ou reelaborando o senso comum. E entender a prática midiática significa uma disposição para compreender o que há além daquilo que finalmente se torna explícito textualmente. Antecipando, inclusive, que tudo o que foi dito ou escrito ocupou um espaço privilegiado, negado a outras possibilidades diferentes de dizer uma determinada coisa, e que são silenciadas no jogo de forças da produção discursiva. A linguagem, já diria Bakhtin ${ }^{18}$, como território onde se materializa essa prática, não é neutra, e é através dela que a mídia exercita o poder e 
as respectivas forças de imposição e de (re) significação da realidade que esse poder arregimenta.

Com base nessa abordagem teórica, constatamos que a crítica através da ideia de ausência, especialmente a ausência de tecnologias e de recursos humanos no Sistema Único de Saúde, foi demarcada textualmente pelo Diário do Nordeste em virtude da visibilidade conferida a essa não oferta, ressaltando tanto quanto possível que tal presença poderia impactar positivamente a vida dos usuários do Sistema. Então, para iniciar a análise dessa ausência, trazemos um texto publicado no dia 6 de fevereiro, na editoria Cidade, que divulgou a aquisição, por um programa público de saúde em funcionamento no estado, de 16 novos corações artificiais a serem implantados em pacientes que esperam pelo transplante de um coração real, alargando seu tempo de vida. Explicando o funcionamento do aparelho, o texto diz que o coração artificial "faz as vezes do coração que está muito comprometido, mantendo o paciente vivo e estabilizado". Dessa maneira, a legitimidade da tecnologia, aqui representada pelo coração artificial, se assegura pelas marcas discursivas do seu efeito, como algo capaz de garantir a vida de alguém que sofre com um coração natural comprometido, à espera de um transplante.

A marca discursiva da ausência do investimento em tecnologia aparece quando o jornal afirma que "o problema é que o Sistema Único de Saúde ainda não financia os corações artificiais para o Estado" (Ver Quadro 1). A ideia sugerida é de que existe um investimento comprovadamente eficaz, mas que falta no Sistema Único de Saúde, reforçada pelo subentendido provocado pela palavra ainda, que pode representar uma ruptura sobre uma coisa estabelecida (o não financiamento) por meio de uma possibilidade de mudança: o que ainda não é pode vir a ser, se for do interesse de quem provém. Há um reforço discursivo da sua importância do ponto de vista de sua utilidade, o que pode ser conferido no trecho: "Desde o início do programa do hospital, 13 aparelhos já foram adquiridos pelo hospital, implantados em sete pacientes, dos quais cinco chegaram ao transplante e sobreviveram como se não tivessem necessitado do dispositivo".

Essa ausência de tecnologia foi também percebida em outro texto, "Vencendo tabus e preconceitos", desta vez no caderno Vida, que se intitula como suplemento de saúde do periódico. Nesse texto, o Diário promove a divulgação da realização de um determinado procedimento cirúrgico, considerado eficiente pelo sistema de saúde privado. O texto versa sobre tratamento para uma doença, incontinência urinária, qualificando positivamente esse tratamento ao destacar os procedimentos "muito eficazes e minimamente invasivos" já disponíveis aos usuários, mas não os do Sistema Único de Saúde, proibitivamente, pois "o ponto negativo é que este tipo de material ainda não está facilmente disponível no Sistema Único de Saúde", como explicitou o texto. O trecho em destaque leva a crer que há um único ponto negativo para o tratamento, anunciado pelo artigo definido 'o' (e não 'um', que conotaria uma indefinição), que é justamente a sua ausência na rede pública. E o termo 'ainda', mais uma vez, exerce o papel da instabilidade em torno da qual a questão parece não estar definitivamente resolvida.

Quadro 1 - Textos com marcas de crítica ao Sistema Único de Saúde

\begin{tabular}{|c|c|c|c|}
\hline Textos & Sentidos & Marcas discursivas & Editoria/Data \\
\hline $\begin{array}{l}\text { Ceará recebe } 16 \\
\text { corações artificiais }\end{array}$ & \multirow{2}{*}{$\begin{array}{l}\text { Ausência de } \\
\text { tecnologias no } \\
\text { Sistema Único } \\
\text { de Saúde }\end{array}$} & $\begin{array}{l}\text { "O problema é que o Sistema Único de Saúde ainda não } \\
\text { financia os corações artificiais para o Estado" }\end{array}$ & $\begin{array}{c}\text { Cidade } \\
19 / 02\end{array}$ \\
\hline $\begin{array}{l}\text { Vencendo tabus e } \\
\text { preconceitos }\end{array}$ & & $\begin{array}{l}\text { "o ponto negativo é que este tipo de material ainda não } \\
\text { está facilmente disponível no Sistema Único de Saúde" }\end{array}$ & $\begin{array}{l}\text { Caderno Vida } \\
19 / 02\end{array}$ \\
\hline $\begin{array}{l}\text { Crise financeira } \\
\text { atinge } 29 \text { hospitais } \\
\text { filantrópicos no CE }\end{array}$ & \multirow{4}{*}{$\begin{array}{l}\text { Precariedade } \\
\text { a partir do } \\
\text { financiamento }\end{array}$} & $\begin{array}{l}\text { "As demandas crescentes e os problemas de } \\
\text { financiamento do Sistema Único de Saúde já fizeram dez } \\
\text { unidades fecharem as portas em quatro anos" }\end{array}$ & $\begin{array}{l}\text { Capa (Manchete - } \\
\text { principal) } \\
19 / 02\end{array}$ \\
\hline \multirow{2}{*}{$\begin{array}{l}80 \% \text { das unidades } \\
\text { filantrópicas do Estado } \\
\text { estão no vermelho }\end{array}$} & & $\begin{array}{c}\text { "As entidades, que são mantidas com a contribuição } \\
\text { do Sistema Único de Saúde e da sociedade, enfrentam } \\
\text { subfinanciamento" }\end{array}$ & \multirow{3}{*}{$\begin{array}{l}\text { Cidade } \\
19 / 02 \\
\text { Cidade } \\
19 / 02\end{array}$} \\
\hline & & $\begin{array}{c}\text { "as instituições atuam para dar suporte a um sistema } \\
\text { público de saúde que há muitos anos funciona acima do } \\
\text { limite" }\end{array}$ & \\
\hline $\begin{array}{l}\text { Santa Casa atende } \\
\text { apenas a } 50 \% \text { de sua } \\
\text { capacidade }\end{array}$ & & $\begin{array}{c}\text { "Defasagem da tabela do Sistema Único de Saúde e } \\
\text { limite contratual imposto pela Prefeitura são as causas } \\
\text { das vagas ociosas" }\end{array}$ & \\
\hline
\end{tabular}


O que chamamos de efeito de sentido de ausência se tece justamente pela escolha dessas palavras, dessas marcas discursivas, e não de outras, provocando no leitor a impressão do vazio, da inexistência no Sistema Único de Saúde, intencional, de uma tecnologia já presente no mercado. Nessas situações, é uma relação com o sistema econômico a partir do consumo das inovações, com a própria tecnologia de ponta disponível e à venda no setor saúde, que é colocada sutilmente em cena pelo jornal. Constrói-se a ideia de que o usuário do Sistema Único de Saúde não pode consumir a novidade ("implante de slings on minislings") porque, segundo o jornal, quem deveria pagar por isso, o Estado, não o faz.

O que a Semiologia dos Discursos Sociais nos ensina sobre as estratégias discursivas é que por meio delas "se travam batalhas que, no nosso dia a dia, levam os participantes de um processo comunicacional a procurar 'dar a última palavra', isto é, a ter reconhecido pelos receptores o aspecto hegemônico do seu discurso" 15 (p. 28). Essa ausência de procedimentos tecnológicos modernos no Sistema Único de Saúde, apresentada pelos textos discutidos, contracena com um cenário de sofrimento, que advém do sentido de precariedade, que pode ser a qualquer momento acionado pela memória do leitor de outros textos de denúncia que continuamente desabrocham nas mídias tradicionais, e as noções se reforçam e se fortalecem mutuamente. Ao demarcar a impossibilidade da oferta pela falta de decisão política, o jornal tanto aponta os responsáveis pela situação quanto exerce seu julgamento, construindo a ideia de que o Sistema Único de Saúde fica atrás das iniciativas privadas de intervenção, mais modernas e menos invasivas, enquanto para ele sobram as filas, as esperas e os procedimentos mais rudes e atrasados. Além disso, é discursivamente significativo que, junto com a visão precarizada sobre o Sistema Único de Saúde, se aponte também um modo de se entender e se legitimar certos significados para saúde, medicina, tratamento: um consumo de inovações, uma relação com a doença e os tratamentos totalmente permeada pelas tecnologias. E o jornal se posiciona mediante a expectativa de que o Estado proporcione isso para o cidadão comum por intermédio do Sistema Único de Saúde.

Outrossim, o sentido de precariedade segue sua conformidade em função do destaque em torno dos problemas de financiamento, de gestão, de estrutura, de insumos, de recursos humanos etc. No caso que vamos explicitar agora, o Sistema Único de Saúde existe, está presente, mas a maneira como funciona é cercada de tantos problemas que se torna inviável acreditar na sua efetividade e, menos ainda, na sua eficiência. Uma das principais estratégias que o jornal usa para construir a ideia de precariedade é pela naturalização da ideia de baixo financiamento do Sistema Único de Saúde, mesmo que de forma fragmentada, já que muitas vezes não há como saber de quem é a real responsabilidade por isso, se da União, do Estado ou do Município. A série de matérias que coletamos sobre as ameaças de paralisação das Santas Casas, motivadas pela debilidade no financiamento, regulado pela tabela de pagamentos do Sistema Único de Saúde, ilustra esse sentido de precariedade. Elas foram publicadas no dia 19 de fevereiro, como manchetes da edição, ocupando duas metades de páginas no Primeiro Caderno, na editoria de Cidade. Na capa, a manchete foi "Crise financeira atinge 29 hospitais filantrópicos no CE". Já os dois textos internos trouxeram como títulos: "80\% das unidades filantrópicas do Estado estão no vermelho"; e "Santa Casa atende apenas a $50 \%$ de sua capacidade".

Verificamos já na capa que o jornal escolheu a palavra Crise para iniciar a chamada, seguida da forma verbal atinge. Uma associação quase automática à palavra Crise é a de um grande problema, algo sobre o qual se permitiu atingir um ponto de insolubilidade, uma parada obrigatória no fluxo dos acontecimentos. Somada ao verbo atingir, remete-nos à ideia um alvo alcançado, golpeado, no caso a Santa Casa de Misericórdia e, num contexto sociocultural mais amplo, a própria filantropia no Brasil, atingida, sobretudo, por medidas macroeconômicas. O texto da chamada é o seguinte: "As demandas crescentes e os problemas de financiamento do Sistema Único de Saúde já fizeram dez unidades fecharem as portas em quatro anos". E segue afirmando que os hospitais atravessam "grave crise", por "problemas de financiamento", em 29 das 36 casas filantrópicas, um percentual de $80 \%$.

Na primeira matéria da reportagem, além da sinalização da altíssima porcentagem no título, a chamada fala do Estado, que se refere à instituição, ao poder governamental, e não do estado, que caracterizaria a região da qual se fala, o Ceará. Dizer dessa maneira faz com que o leitor acione uma crítica pré-existente sobre a própria concepção de gestão pública como precária ou, por qualquer razão, ineficiente. No intertítulo, o jornal traz o enunciado "As entidades, que são mantidas com a contribuição do Sistema Único de Saúde e da sociedade, enfrentam subfinanciamento". No segundo parágrafo, a repórter arremata a noção de caos 
num tempo já antigo, do passado, e que se estende na contemporaneidade, quando afirma que "as instituições atuam para dar suporte a um sistema público de saúde que há muitos anos funciona acima do limite".

A segunda matéria tem início com o uso de um percentual significativo: $50 \%$. Imediatamente somos convocados a perceber que a metade, e apenas a metade, de um serviço extremamente necessário à população está em funcionamento. E a responsabilidade, para que não reste dúvida, é da defasagem da tabela do Sistema Único de Saúde "Defasagem da tabela do Sistema Único de Saúde e limite contratual imposto pela Prefeitura são as causas das vagas ociosas". Nesse sentido, faz-se presente a ideia de um Sistema que provoca males à filantropia, impedindo que ela funcione plenamente.

Sobre a precariedade do financiamento, é importante observar que essa presença, esse não esquecimento do assunto no jornal, e até uma aparente naturalidade que se cria pela repetição dos argumentos, é uma agenda de diversos movimentos que militam em favor do Sistema Único de Saúde, e que encontra eco na mídia. O subfinanciamento do Sistema é uma ideia simpática tanto à arena política quanto midiática. Até há quem afirme que esse não é o único problema, mas é difícil encontrar quem discorde de que esse é sim um agravante. Para além dessa ideia central, no entanto, sobra pouco consenso. Os sujeitos políticos envolvidos no processo de transformação dessa realidade, entre eles a mídia, têm formas diferentes de interpretá-la e de atribuir responsabilidades sobre o fato. Ao não acreditar na transparência da linguagem, tampouco na neutralidade dos sujeitos, a análise dos discursos nos ensina a posicionar a prática midiática no contexto dos interesses estruturais, sobretudo econômicos, que a inspiram. Assim, destacar a precariedade do financiamento do Sistema Único de Saúde é acionar uma rede de sentidos cujo principal objetivo é a sua desqualificação, esvaziando a competência do Estado para gerir as políticas de seguridade social. E para estar presente nas regiões e para os sujeitos que mais necessitam de políticas públicas eficazes.

Ajuda na compreensão desse processo discursivo o entendimento do contexto histórico de constituição do jornalismo brasileiro, que muito se modificou e se beneficiou do ideário de construção da democracia e radicalização do capitalismo enquanto regime econômico e modo de subjetivação do indivíduo contemporâneo. Abreu $^{19}$ destaca que a imprensa brasileira se situou histórica e estrategicamente nesse lugar simbólico de negociação entre a democracia recém-instalada e as necessidades de novos cidadãos que emergiram, ou foram forjados, a partir dela - mais preocupados em ter acesso à liberdade, aos direitos e aos serviços públicos e privados. O jornalismo passou, assim, a cobrar respostas, visibilizar (ou invisibilizar) a opinião de públicos, ao mesmo tempo em que progressivamente se comprometeu com os princípios basilares do mercado. O Sistema Único de Saúde, como política pública, é um tema cujo valor enquanto notícia passa por essa relação.

Entretanto, não foram apenas negativos os modos de falar sobre o Sistema Único de Saúde nomeado. Percebemos no corpus para este estudo a recorrência de dois sentidos de reconhecimento do Sistema: de eficácia e de valorização com base na tradição do serviço. Vejamos o Quadro 2.

Os sentidos de eficácia foram produzidos especialmente através da narrativa de serviços que funcionam e que correspondem às expectativas daqueles que os solicitam. Dessa forma, o jornal construiu um jogo discursivo que tornou reais, a partir do registro da existência, tanto as ações e serviços precários quanto o seu oposto. Esse jogo constitui a prática social midiática, pois reforça o seu papel

Quadro 2 - Textos com marcas discursivas de reconbecimento ao Sistema Único de Saúde

\begin{tabular}{|l|c|rc|c|}
\hline Textos & Sentidos & Marcas discursivas & Editoria/Data \\
\hline $\begin{array}{l}\text { Menos feridos respiram } \\
\text { com a ajuda de aparelhos }\end{array}$ & Eficácia & $\begin{array}{l}\text { "Segundo a Força Nacional do Sistema Único de Saúde, uma } \\
\text { equipe com 120 profissionais segue em Santa Maria para dar } \\
\text { apoio psicológico e psiquiátrico a familiares e amigos das vítimas" }\end{array}$ & $\begin{array}{c}\text { Nacional } \\
03 / 02\end{array}$ \\
\hline $\begin{array}{l}\text { Hospital do Cariri já } \\
\text { fez mais de } 80 \text { mil } \\
\text { atendimentos }\end{array}$ & Eficácia & $\begin{array}{l}\text { "... serviços pioneiros na área de saúde pública, como a } \\
\text { ressonância magnética em pacientes do Sistema Único de } \\
\text { Saúde" }\end{array}$ & $\begin{array}{c}\text { Regional } \\
28 / 02\end{array}$ \\
\hline $\begin{array}{l}\text { Instituição já celebra } 80 \\
\text { anos }\end{array}$ & Tradição & $\begin{array}{l}\text { "...oferece aos pacientes do Sistema Único de Saúde (SUS) } \\
\text { tratamentos de ponta e procedimentos de alta complexidade, } \\
\text { ainda não disponíveis no Norte e Nordeste e até em outras } \\
\text { regiões do Brasil" }\end{array}$ & $\begin{array}{c}\text { Cidade } \\
11 / 05\end{array}$ \\
\hline
\end{tabular}


de protetor do interesse público, no qual cabe o alerta e a denúncia, mas também o reconhecimento e a legitimação como estratégias que se complementam e possibilitam um aparente equilíbrio tanto na arena discursiva midiática quanto nas incertezas que caracterizam a própria sociedade reflexiva, da qual a mídia, assim como todos nós sujeitos contemporâneos, é signatária.

Oliveira $^{20}$, revisitando o pensamento de Ulrich Beck, define que esse tipo de sociedade, de organização social, como aquela onde se alterou substancialmente a maneira de viver, saindo de uma ação/reflexão antes mais voltada para o passado, nas sociedades tradicionais, e agora mais empenhada e preocupada com o futuro, tendo que, por isso, "conviver com a turbulência dos riscos provocados pelos efeitos da modernidade que trazem consigo uma espécie de insegurança ontológica para os seus membros" ${ }^{20}$ (p. 2). Sendo a mídia hoje, mais que um canal de informações, uma espécie de termômetro do funcionamento do mundo, seria extremamente difícil e talvez inconveniente ressaltar apenas o lado negativo de uma política pública que assiste a maior parte da população do país.

A cobertura do incêndio na boate Kiss, grande tragédia que abalou o País em janeiro de 2013, e a atuação do Sistema Único de Saúde nos desdobramentos do caso, explicitam esse jogo de contradição e equilíbrio, construindo sentidos de eficácia com base no reconhecimento das práticas exitosas do Sistema. Na matéria publicada no dia 3 de fevereiro, com o título "Menos feridos respiram com a ajuda de aparelhos", o leitor viu emergir no jornal um sujeito discursivo, a Força Nacional do Sistema Único de Saúde, criada pelo Governo Federal como uma estratégia de enfrentamento a tragédias. Chamamos de sujeito porque tal força-tarefa tornou-se um personagem na continuidade da cobertura, detentor de uma fala, constituído alicerçado nas ações que desenvolveu, nas fotos onde apareceu resgatando os sobreviventes, prestando suporte mental, e da autoridade que assumiu para emitir boletins médicos, divulgando o estado das vítimas. A matéria diz: "Segundo a Força Nacional do Sistema Único de Saúde, uma equipe com 120 profissionais segue em Santa Maria para dar apoio psicológico e psiquiátrico a familiares e amigos das vítimas".

Percebemos que esse Sistema Único de Saúde que funciona foi revelado também a partir de uma dinâmica de relação do jornal, de uma mediação do Diário, com os mais expressivos sujeitos do discurso. Em certos momentos, o jornal criou mecanismos de ressignificação desses sujeitos, que se foram responsabilizados por sentidos mais negativos para o Sistema em algumas situações, em outros ocorreu o contrário, e foram partícipes de uma imagem mais positiva do Sistema Único de Saúde. A relação do jornal com o governo do Estado ilustra bem essa dinâmica. O acompanhamento progressivo da cobertura nos possibilitou perceber que esse governo ocupa lugares distintos, sendo mais ou menos reconhecidos, a medida que isso se tornou conveniente para o jornal e a cobertura proposta. Essa dinâmica influenciou na formação do sentido de eficácia, presente, por exemplo, no texto "Hospital do Cariri já fez mais de 80 mil atendimentos". Nele, o jornal promove a divulgação positiva de um hospital que é público, que atende exclusivamente pelo Sistema Único de Saúde, mas que foi construído pela atual gestão estadual.

No trecho "serviços pioneiros na área de saúde pública, como a ressonância magnética em pacientes do Sistema Único de Saúde" essa funcionalidade se caracteriza pela ideia localizada da oferta de tecnologia de imagem em pacientes do Sistema Único de Saúde no Ceará. Uma oferta apresentada como uma coisa pioneira, que não havia antes, e que passou a ser promovida pelo Governo do Estado. O Sistema Único de Saúde passa a ser valorado por iniciativas de um governo específico. Vale mencionar que esse texto é parte de uma reportagem que ocupa a página inteira do jornal e foi chamada de capa da edição. Além do uso de imagens de usuários, há a vocalização deles em boxes, e este foi um dos poucos registros em que os usuários foram convocados pelo jornal para falar de forma positiva sobre um serviço do Sistema Único de Saúde.

Há, ainda, um jogo de reconhecimento baseado na tradição, que legitima o hospital pela sua antiguidade. Por essa estratégia discursiva, o periódico construiu um sentido de serviço de referência, que resistiu ao passar do tempo superando todas as crises e cumprindo o seu papel. Isso foi visto na matéria "Instituição já celebra 80 anos", sobre um hospital público que se tornou referência em transplantes, especialmente de pulmão, no Nordeste. Segundo o jornal, o Hospital de Messejana "oferece aos pacientes do Sistema Único de Saúde (SUS) tratamentos de ponta e procedimentos de alta complexidade, ainda não disponíveis no Norte e Nordeste e até em outras regiões do Brasil". Aqui é possível perceber uma oposição a uma precariedade anteriormente apresentada, de tecnologias: este Sistema Único de Saúde praticado no Hospital de Messejana oferece tratamento de ponta. 


\section{CONCLUSÃO|}

A busca por uma compreensão mais aprofundada sobre os modos pelos quais os jornais constroem sentidos sobre o Sistema Único de Saúde, em especial o jornal Diário do Nordeste, nos levou a problematizar a prática recorrente de atribuir a eles, bem como à grande mídia de maneira geral, a construção de uma imagem negativa do Sistema Único de Saúde, mencionada em diversos discursos e estudos $3,4,5,6,7,8$. Dos 132 textos nomeados, optamos por nos aprofundar naqueles que promovem a crítica com base nos sentidos de 'ausência' de tecnologias, e pelo sentido de 'precariedade'; mas também promovem um reconhecimento em função da ideia de 'eficácia' e das narrativas de serviços considerados de 'tradição'.

Podemos inferir que há em cada um dos múltiplos olhares sobre o Sistema Único de Saúde narrados pelo jornal o implícito do oposto, do 'outro' da linguagem. Assim, quando, por exemplo, o Diário afirma que algo não funciona, há ali uma ideia de funcionalidade, um parâmetro político ou estrutural para a realização de tal avaliação. Ao caracterizar uma ausência de tecnologias, é pelo registro da presença e do sucesso delas que o jornal legitima um investimento nelas. Da mesma forma, quando um serviço é dado como referência, o próprio ato de destacálo representa uma valorização que só é relevante porque diferencia tal serviço do seu oposto, daquele que não pode ser considerado referencial.

Assim, a análise do Diário do Nordeste nos apontou a presença de uma série de deslocamentos de sentidos que podem ser qualificados para além da simples adjetivação negativa ao sujeito Sistema Único de Saúde. Ao falar da ausência de tecnologias, por exemplo, há um par de oposição imediato que é a iniciativa pública $\mathrm{x}$ iniciativa privada, como se a condição para a qualificação das ações e procedimentos de saúde fosse a entrada de capital privado no Sistema Único de Saúde, ou mesmo sua privatização. Nesse sentido, além de adjetivar o Sistema, a mídia cria, pelos mecanismos do discurso, situações relativas, cuja funcionalidade pode ou não mudar de um dia para o outro, de um contexto para o outro, de interlocutor a interlocutor, articulandose, inclusive, com o cenário político/partidário vigente. O Diário do Nordeste é um jornal cuja linha editorial não raramente se compromete com o governismo em situação, e este é um contexto precioso para a fundamentação sociopolítica presente nas análises de discursos.
Com muita regularidade, a mídia critica e também reconhece o Sistema Único de Saúde, e esses sentidos podem, inclusive, aparecer juntos, dividindo a mesma superfície textual e o mesmo contexto produtivo do dispositivo jornalístico (o tempo, as condições de apuração, as fontes consultadas etc.). Nisso reside uma importante assertiva: as estratégias discursivas empreendidas pelo Diário mostram tanto sobre o Sistema Único de Saúde na mídia, os seus efeitos de sentidos, quanto sobre o próprio jornalismo e a forma como o jornal se posiciona, marcando seu lugar de fala como ator político que luta pelo 'bem comum', que toma para si o papel de defender os interesses da democracia, atuando como um fiscal socialmente autorizado para tal. Nesse exercício político, pelas mediações desempenhadas, o jornal assegura e reforça o seu próprio poder simbólico, a sua legitimidade referencial na esfera pública, como autoridade para produzir realidades.

Assim, ao falar bem e também falar mal do Sistema Único de Saúde, há uma articulação de poder midiático que nos possibilita enxergar além das práticas discursivas existentes de negativação desse Sistema. O principal achado desta pesquisa talvez seja justamente problematizar as distintas e diversas representações que a mídia constrói sobre o Sistema Único de Saúde, com base em seus discursos, porque ela promove visibilidades e também invisibilidades nas suas estratégias de criticar e reconhecer, e tais dinâmicas se sedimentam por meio de jogos políticos de moderação na esfera pública. Da mídia com a sociedade, da mídia com os políticos etc. São sempre os capitais envolvidos - financeiro, simbólico, estrutural, profissional - que fundamentam as negociações e dão os tons de suas práticas sociais, que são, por isso mesmo, muito mais complexas do que as explicações sobre objetividade, ou sobre imparcialidade/ parcialidade, nos fazem crer.

\section{REFERÊNCIAS |}

1. Brasil. Ministério da Saúde. Agência Nacional de Saúde Suplementar. Caderno de informação da saúde suplementar: beneficiários, operadoras e planos [Internet]. Rio de Janeiro: Ministério da Saúde; 2014 [acesso em 28 mar 2016]. Disponível em: URL: <http://migre.me/tnbEs>.

2. Paim JS. O que é o SUS. Rio de Janeiro: Fiocruz; 2009. 
3. Santiago AMV. Análise da imprensa escrita sobre o SUS no sistema municipal de saúde de Fortaleza entre 2005 e 2008. Fortaleza. Dissertação [Mestrado em Saúde Pública]. - Universidade Federal do Ceará; 2010.

4. Silva GM. A crítica ao SUS no jornal Folha de São Paulo. Uberlândia. Dissertação [Mestrado Psicologia Aplicada] Universidade Federal de Uberlândia; 2010.

5. Menegon VSM. Crise dos serviços de saúde no cotidiano da mídia impressa. Psicol Soc. 2008; 20(nº esp):32-40.

6. Xavier C, Narvai PC. A marca invisível do SUS. Ensaios \& Diálogos. 2015; 1(1):45-9.

7. Lefèvre F, Caron E. A saúde mediada pela televisão: o caso do Jornal Nacional. In: Sacramento I, organizador. Mediações comunicativas da saúde. Rio de Janeiro: Multifoco; 2017. p. x-x.

8. Oliveira VC. A comunicação midiática e o Sistema Único de Saúde. Interface (Botucatu). 2000; 4(7):71-80.

9. Instituto de Pesquisa Econômica Aplicada [Internet]. SIPS 2011: Sistema de Indicadores de Percepção Social [acesso em 13 nov 2017]. Disponível em: URL: <http:// www.ipea.gov.br/portal/index.php?option $=$ com_ content\&view $=$ article $\&$ id $=24420 \&$ catid $=120 \&$ Itemid $=2>$.

10. Collucci C. Classe média se surpreende com o "SUS que funciona" [Internet]. Folha de São Paulo 2016 abr 12 [acesso em 13 nov 2017]. Disponível em: URL: <http://www1.folha.uol.com.br/colunas/ claudiacollucci/2016/04/1759908-classe-media-sesurpreende-com-o-sus-que-funciona.shtml>.

11. O SUS que dá certo [Internet]. Globo 2017 jul 22 [acesso em 13 nov 2017]. Disponível em: URL: <http:// g1.globo.com/como-sera/noticia/2017/07/o-sus-que-dacerto.html>.

12. Machado IB. Percepções sobre o SUS: o que a mídia mostra e o revelado em pesquisa. In: Lerner $\mathrm{K}$, Sacramento I, organizadores. Saúde e jornalismo: interfaces contemporâneas. Rio de Janeiro: Fiocruz; 2014. p. 235-50.

13. Cavalcante CC. Os sentidos do Sistema Único de Saúde na mídia impressa do Ceará: um estudo do jornal O Diário do Nordeste. Rio de Janeiro. Dissertação [Mestrado em Informação e Comunicação em Saúde] - Fundação Oswaldo Cruz; 2014.

14. FTPI Inteligência em Regionalização [Internet]. Diário do Nordeste [acesso em 14 jan 2014]. Disponível em: URL: $<$ http://ftpi.com.br/jornal/diario-do-nordeste/>.

15. Pinto MJ. Comunicação e discurso: introdução à análise de discursos. 2. ed. São Paulo: Hacker; 2002.

16. Bourdieu P. O poder simbólico. 16. ed. Rio de Janeiro: Bertrand Brasil; 2012.

17. Araújo IS. Mercado simbólico: um modelo de comunicação para políticas públicas. Interface (Botucatu). 2004; 8(14):165-78.

18. Bakhtin M. Marxismo e filosofia da linguagem. 12. ed. São Paulo: Hucitec; 2006.

19. Abreu AA. Jornalismo cidadão. Estudos Históricos. 2003; 1(31):25-40.

20. Oliveira VC. Os sentidos da saúde nas mídias jornalísticas impressas. R Eletr de Com Inf Inov Saúde [Internet]. 2013 [acesso em 01 abr 2016]; 6(4). Disponível em: URL: <http://www.reciis.icict.fiocruz.br/index.php/ reciis/article/view/622/1262>.

Correspondência para/Reprint request:

Clarisse Castro Cavalcante

Rua Pedro Celeste, 75, casa 2, Cruzeiro do Sul, Juiz de Fora/MG, Brasil CEP: 36030-140

E-mail: clarissecastrocavalcante@gmail.com

Submetido em: 09/06/2017

Aceito em: 17/11/2017 